\title{
Metal Micro-Forming
}

\author{
Ken-ichi Manabe \\ Department of Mechanical Systems Engineering, Tokyo Metropolitan University, 1-1 Minamiosawa, \\ Hachioji-shi 192-0397, Japan; manabe@tmu.ac.jp
}

Received: 8 June 2020; Accepted: 16 June 2020; Published: 18 June 2020

\section{Introduction}

Metal micro-forming is the technological field of micro-manufacturing. It is a microfabrication technology for micro parts that takes advantage of the excellent mechanical and functional characteristics peculiar to metal, and is a vital forming technology that has been scaled down to the microscale range suitable for mass production. Yole Développement [1] predicts that the compound annual growth rate (CAGR) of the micro electromechanical systems (MEMS) market in micro-manufacturing from 2018 to 2024 is $43.6 \%$ for telecom applications, 7.5\% for medical applications and 11.0\% for industry applications. These are mainly related to the semiconductor market. Similarly, the market prediction for metal micro-components with the excellent characteristics of metals is also expected to grow.

Investigations into metal micro-forming technology have been developing over the last 20 years. These studies include research and development activity for micro-bulk forming, micro-sheet metal forming, micro-hydroforming, laser-assisted micro-forming, surface engineering for die and tooling, embossing and micro-sintering. Among them, the elucidation of the size effect associated with scale-down in each processing method is one of the central issues, and its fundamental research and new special processing technology has been developed.

The purpose of this Special Issue is to collect expert views and contributions on the present achievements on metal micro-forming, and through this issue, to find present challenges and to offer ideas for possible solutions.

\section{Contributions}

In this Special Issue, there are nine papers related to conventional metal forming processes, and two basic testing and evaluation methods (surface roughening and evaluation of micro-tribological characteristics with lubricants); a total of 11 papers. Their processing is categorized into nine methods: tube forming, wire drawing, wire rolling, orbital forging, ring-shape forging, channel forming and embossing. As a basic common characterization, it contains two themes: the micro-tribological characteristics of surface texture on a micro die and the surface roughening evaluation test of raw material. Some techniques are assisted by temperature (high-frequency induction heating and resistance heating) and others by ultrasonic vibration, hydroforming and shock wave liquid medium high-energy-rate processing. Examples of copper, titanium, aluminum, stainless steel and the metallic powders of stainless steel and aluminum are used for medical and communication fields.

So far, relatively few review articles on the forming technology of micro-tubes have been published. It is welcome, therefore, that Hartl [2] reviews and classifies the recent progress in research and development on the fabrication and secondary metalworking methods of micro-tubes. The various micro tube manufacturing methods include various heat assisted dieless drawing methods, micro tube manufacturing by conventional technology, micro tube fabrication for special tubes and the latest manufacturing technology for micro hydroforming technology for T-shapes and cross shapes, laser heating assisted bending processing, micro tube processing technology using severe plastic deformation and micro tube characteristic evaluation methods. A total of 117 papers are surveyed and 
summarized. Yasui et al. [3] focus on micro T-shape hydroforming of $0.5 \mathrm{~mm}$ diameter micro-tubes and examine the effects of the friction and the length of micro-tube on their hydroformability and material flow, using both experiments and finite element analysis. They confirm that, for a short micro-tube, the friction effect is suppressed and high hydroformability is obtained, but by increasing the length of the tube and friction, the hydroformability decreases.

For microwires, Hwang and Liu [4] examine the effects of processing temperature and the oxide layer on the mechanical properties of the drawn wire in microwire dieless drawing by high-frequency induction heating using fine, $1 \mathrm{~mm}$ diameter stainless steel wire. Additionally, the influence of the drawing speed and the processing temperature on the drawing limit is examined by the finite element dieless drawing analysis. Xie et al. [5] examine the size effect of microstructure on the deformation characteristics of microwires with a flat rolling outer diameter of 1.5 to $0.8 \mathrm{~mm}$ in flat rolling. The effect of the surface layer effect on rolling resistance and the effect of wire diameter on the development of surface roughness.

For micro forging, Presz [6] investigates the material flow related to ultrasonic orbital micro forging, the material flow in different die shapes was clarified in detail by the application of $20 \mathrm{kHz}$ vibration with a $16 \mu \mathrm{m}$ longitudinal amplitude at surface of punch nose to an aluminum cylinder, with a diameter of $1 \mathrm{~mm}$. Yang and Shimizu [7] develop an innovative resistance heating method using a surface-modified punch and evaluate the heating characteristics. The coating effect of the die in the ring-shape forging is tested by applying it to Ti, Cu, SUS304 materials using a die coated with 0.5 and $1 \mu \mathrm{m}$ of $\mathrm{AlCrSiN}$ film, to improve heating characteristics.

As an application of high-energy rate micro-forming technology, Liu et al. [8] develop a laser impact liquid flexible micro-forming process, which was taken up and applied to the forming of a microchannel of copper foil material. The fabricated shape was compared with finite element analysis results.

In terms of the micro metal compaction for micro sintering, Emadinia et al. [9] perform micro hot embossing using aluminum and stainless steel metal powders with carbon nanotube (CNTs), and examine the optimum conditions of the powder component blending ratio to make the green compact uniform, and to improve the surface properties of the compact.

On the other hand, Shimuzu et al. [10] carry out research on basic micro-tribological characteristics related to metal micro-forming technology, investigating the lubrication effect of dimple texture with a diameter of 10,50,100 $\mu \mathrm{m}$ provided on the die surface, which is important for the tribological characteristics in sheet forming, the bending and ironing experiment of $0.1 \mathrm{~mm}$ thick SUS304 foil material. In addition to the finite element forming analysis and computational fluid dynamics analysis (CFD) on die contact lubrication condition, an in-situ observation of lubricant flow is performed to confirm the effect of a dimple array on the die. Furushima et al. [11] propose a new compression test method for thin sheet metals, to characterize the surface roughening evolution under compressive strain, and confirm the surface roughening behavior during the straining of thin sheet.

For micro-die manufacturing, Shiratori et al. [12] develop a manufacturing method of micro-meshing punch array for micro-embossing on copper thin sheet by a low-temperature plasma printing process. A $180 \mu \mathrm{m} \times 180 \mu \mathrm{m}$ square prism array of a thin copper plate is formed by micro-embossing.

\section{Conclusions}

This Special Issue provides a total of 11 articles from seven countries, including one review paper. From these collected papers, it may be seen that micro-forming research in the world is steadily progressing and developing, and it is possible to get a glimpse of the present situation and the academic and technological issues. I hope that advanced metal micro-forming technology will further progress through the elucidation of material deformation behavior in microscale, and that this Special Issue will contribute to prosperous future research. 
I would like to express sincere thanks to all the contributors to this Special Issue. Additionally, to the reviewers for making useful comments, and the Metal Editorial staff for prompt publishing.

Conflicts of Interest: The author declares no conflict of interest.

\section{References}

1. Status of the MEMS Industry 2019. Available online: https://yole-i-micronews-com.osu.eu-west-2.outscale. com/uploads/2019/06/YD19031_Status_of_the_MEMS_industry_2019_Sample_Yole_Developpement.pdf (accessed on 3 June 2020).

2. Hartl, C. Review on advances in metal micro-tube forming. Metals 2019, 9, 542. [CrossRef]

3. Yasui, H.; Yoshihara, S.; Mori, S.; Tada, K.; Manabe, K. Material deformation behavior in T-shape hydroforming of metal microtubes. Metals 2020, 10, 199. [CrossRef]

4. Hwang, Y.-M.; Liu, H.-H. Formability analysis and oxidation layer effects in dieless drawing of stainless steel wires. Metals 2019, 9, 828. [CrossRef]

5. Xie, H.; Manabe, K.; Jiang, Z. Study of wire deformation characterization and size effects during the micro-flat-rolling process. Metals 2020, 10, 405. [CrossRef]

6. Presz, W. Material flow in ultrasonic orbital microforming. Metals 2019, 9, 475. [CrossRef]

7. Yang, M.; Shimizu, T. Development of a novel resistance heating system for microforming using surface-modified dies and evalm, uation of its heating property. Metals 2019, 9, 440. [CrossRef]

8. Liu, F.; Liu, H.; Jiang, C.; Ma, Y.; Wang, X. Experimental and numerical investigations of a novel laser impact liquid flexible microforming process. Metals 2018, 8, 599. [CrossRef]

9. Emadinia, O.; Vieira, M.T.; Vieira, M.F. Feedstocks of aluminum and 316L stainless steel powders for micro hot embossing. Metals 2018, 8, 999. [CrossRef]

10. Shimizu, T.; Kobayashi, H.; Vorholt, J.; Yang, M. Lubrication analysis of micro-dimple textured die surface by direct observation of contact interface in sheet metal forming. Metals 2019, 9, 917. [CrossRef]

11. Furushima, T.; Aoto, K.; Alexandrov, S. A new compression test for determining free surface roughness evolution in thin sheet metals. Metals 2019, 9, 451. [CrossRef]

12. Shiratori, T.; Aizawa, T.; Saito, Y.; Wasa, K. Plasma printing of an AISI316 micro-meshing punch array for micro-embossing onto copper plates. Metals 2019, 9, 396. [CrossRef]

(C) 2020 by the author. Licensee MDPI, Basel, Switzerland. This article is an open access article distributed under the terms and conditions of the Creative Commons Attribution (CC BY) license (http://creativecommons.org/licenses/by/4.0/). 